Internat. J. Math. \& Math. Sci.

Vol. 22, No. 3 (1999) 605-610

S 0161-1712<99>22605-1

(C) Electronic Publishing House

\title{
ON A CLASS OF UNIVALENT FUNCTIONS
}

\section{DINGGONG YANG and JINLIN LIU}

(Received 15 September 1997)

ABSTRACT. We consider the class of univalent functions defined by the conditions $f(z) / z \neq$ 0 and $\left|(z / f(z))^{\prime \prime}\right| \leq \alpha,|z|<1$, where $f(z)=z+\cdots$ is analytic in $|z|<1$ and $0<\alpha \leq 2$.

Keywords and phrases. Univalent functions, subordination.

1991 Mathematics Subject Classification. 30C45.

1. Introduction. Let $A$ denote the class of functions of the form

$$
f(z)=z+\sum_{n=2}^{\infty} a_{n} z^{n}
$$

which are analytic in the unit disk $E=\{z:|z|<1\}$. A function $f(z) \in A$ is said to be star-like in $|z|<r(r \leq 1)$ if and only if it satisfies

$$
\operatorname{Re} \frac{z f^{\prime}(z)}{f(z)}>0, \quad(|z|<r) .
$$

In [2], Nunokawa, Obradovic, and Owa proved the following theorem:

THEOREM A. Let $f(z) \in A$ with $f(z) \neq 0$ for $0<|z|<1$ and let

$$
\left|\left(\frac{z}{f(z)}\right)^{\prime \prime}\right| \leq 1, \quad(z \in E) .
$$

Then $f(z)$ is univalent in $E$.

For $0<\alpha \leq 2$, let $S(\alpha)$ denote the class of functions $f(z) \in A$ which satisfy the conditions

$$
f(z) \neq 0 \quad \text { for } 0<|z|<1
$$

and

$$
\left|\left(\frac{z}{f(z)}\right)^{\prime \prime}\right| \leq \alpha, \quad(z \in E) .
$$

In this paper, we give an extension of Theorem A and obtain some results for the class $S(\alpha)$.

By virtue of a result due to Ozaki and Nunokawa [4], Obradovic et al. [3] considered a class of univalent functions.

\section{A criterion for univalence}

THEOREM 1. Let $f(z) \in A$ with $f(z) \neq 0$ for $0<|z|<1$ and let $g(z) \in A$ be bounded 
in $E$ and satisfy

$$
m=\inf \left\{\left|\frac{g\left(z_{1}\right)-g\left(z_{2}\right)}{z_{1}-z_{2}}\right|: z_{1}, z_{2} \in E\right\}>0 .
$$

If

$$
\left|\left(\frac{z}{f(z)}-\frac{z}{g(z)}\right)^{\prime \prime}\right| \leq K, \quad(z \in E)
$$

where

$$
K=\frac{2 m}{M^{2}} \quad \text { and } \quad M=\sup \{|g(z)|: z \in E\},
$$

then $f(z)$ is univalent in $E$.

Proof. If we put

$$
h(z)=\left(\frac{z}{f(z)}-\frac{z}{g(z)}\right)^{\prime \prime},
$$

then the function $h(z)$ is analytic in $E$ and, by integration from 0 to $z$, we get

$$
\left(\frac{z}{f(z)}-\frac{z}{g(z)}\right)^{\prime}=b_{2}-a_{2}+\int_{0}^{z} h(u) d u
$$

and

$$
\frac{z}{f(z)}-\frac{z}{g(z)}=\left(b_{2}-a_{2}\right) z+\int_{0}^{z} d v \int_{0}^{v} h(u) d u,
$$

where $f(z)=z+a_{2} z^{2}+\cdots$ and $g(z)=z+b_{2} z^{2}+\cdots$.

Thus, we have

$$
f(z)=\frac{g(z)}{1+\left(b_{2}-a_{2}\right) g(z)+g(z)(\psi(z) / z)},
$$

where

$$
\psi(z)=\int_{0}^{z} d v \int_{0}^{v} h(u) d u
$$

Since

$$
\left(\frac{\psi(z)}{z}\right)^{\prime}=\frac{1}{z^{2}} \int_{0}^{z} u \psi^{\prime \prime}(u) d u=\frac{1}{z^{2}} \int_{0}^{z} u h(u) d u,
$$

from (2.2) and (2.4), we get

$$
\left|\left(\frac{\psi(z)}{z}\right)^{\prime}\right| \leq \int_{0}^{1} t|h(z t)| d t \leq \frac{K}{2},
$$

and so

$$
\left|\frac{\psi\left(z_{2}\right)}{z_{2}}-\frac{\psi\left(z_{1}\right)}{z_{1}}\right|=\left|\int_{z_{1}}^{z_{2}}\left(\frac{\psi(z)}{z}\right)^{\prime} d z\right| \leq \frac{K}{2}\left|z_{2}-z_{1}\right|
$$

for $z_{1}, z_{2} \in E$ and $z_{1} \neq z_{2}$.

If $z_{1} \neq z_{2}$ then $g\left(z_{1}\right) \neq g\left(z_{2}\right)$ and it follows, from (2.7) and (2.11), that 


$$
\begin{aligned}
\mid f\left(z_{1}\right) & -f\left(z_{2}\right) \mid \\
& =\frac{\left|g\left(z_{1}\right)-g\left(z_{2}\right)+g\left(z_{1}\right) g\left(z_{2}\right)\left(\frac{\psi\left(z_{2}\right)}{z_{2}}-\frac{\psi\left(z_{1}\right)}{z_{1}}\right)\right|}{\left|1+\left(b_{2}-a_{2}\right) g\left(z_{1}\right)+g\left(z_{1}\right) \frac{\psi\left(z_{1}\right)}{z_{1}}\right|\left|1+\left(b_{2}-a_{2}\right) g\left(z_{2}\right)+g\left(z_{2}\right) \frac{\psi\left(z_{2}\right)}{z_{2}}\right|} \\
& >\frac{\left|g\left(z_{1}\right)-g\left(z_{2}\right)\right|-M^{2} K \frac{\left|z_{1}-z_{2}\right|}{2}}{\left|1+\left(b_{2}-a_{2}\right) g\left(z_{1}\right)+g\left(z_{1}\right) \frac{\psi\left(z_{1}\right)}{z_{1}}\right|\left|1+\left(b_{2}-a_{2}\right) g\left(z_{2}\right)+g\left(z_{2}\right) \frac{\psi\left(z_{2}\right)}{z_{2}}\right|} \geq 0 .
\end{aligned}
$$

Hence, $f(z)$ is univalent in $E$.

COROLlary 1. Let $f(z) \in A$ with $f(z) \neq 0$ for $0<|z|<1$. If

$$
\left|\left(\frac{z}{f(z)}\right)^{\prime \prime}\right| \leq 2, \quad(z \in E),
$$

then $f(z)$ is univalent in $E$. The bound 2 in (2.13) is best possible.

Proof. Setting $g(z)=z$ in Theorem 1 , we conclude that $f(z)$ is univalent in $E$ for $f(z)$ satisfying condition (2.13).

To show that the result is sharp, we consider

$$
f(z)=\frac{z}{(1+z)^{2+\epsilon}}, \quad(\epsilon>0)
$$

Note that

$$
\left|\left(\frac{z}{f(z)}\right)^{\prime \prime}\right|=(2+\epsilon)(1+\epsilon)|1+z|^{\epsilon}, \quad(z \in E)
$$

and $f^{\prime}(1 /(1+\epsilon))=0$. Hence, $f(z)$ is not univalent in $E$ and the proof is complete.

From Corollary 1, we easily get

COROLlary 2. Let

$$
f(z)=\frac{z}{1+\sum_{n=1}^{\infty} b_{n} z^{n}} \in A
$$

and

$$
\sum_{n=2}^{\infty} n(n-1)\left|b_{n}\right| \leq 2
$$

Then $f(z)$ is univalent in $E$.

3. The class $S(\alpha)$. According to Corollary 1, all the functions in $S(\alpha)(0<\alpha \leq 2)$ are univalent in $E$. Let the functions $f(z)$ and $g(z)$ be analytic in $E$. Then $f(z)$ is said to be subordinate to $g(z)$, written $f(z) \prec g(z)$, if there exists a function $w(z)$ analytic in $E$, with $w(0)=0$ and $|w(z)|<1(z \in E)$, such that $f(z)=g(w(z))$ for $z \in E$.

For our next results, we need the following. 
LEMMA 1 [5]. Let $f(z)$ and $g(z)$ be analytic in $E$ with $f(0)=g(0)$. If $h(z)=z g^{\prime}(z)$ is star-like in $E$ and $z f^{\prime}(z) \prec h(z)$, then

$$
f(z) \prec g(z)=g(0)+\int_{0}^{z} \frac{h(t)}{t} d t .
$$

THEOREM 2. Let $f(z)=z+a_{2} z^{2}+\cdots \in S(\alpha)$ with $0<\alpha \leq 2$. Then, for $z \in E$,

$$
\begin{aligned}
\left|\frac{z}{f(z)}-1\right| & \leq|z|\left(\left|a_{2}\right|+\frac{\alpha}{2}|z|\right) ; \\
1-|z|\left(\left|a_{2}\right|+\frac{\alpha}{2}|z|\right) & \leq \operatorname{Re} \frac{z}{f(z)} \leq 1+|z|\left(\left|a_{2}\right|+\frac{\alpha}{2}|z|\right) ; \\
|f(z)| & \geq \frac{|z|}{1+\left|a_{2}\right||z|+\frac{\alpha}{2}|z|^{2}} .
\end{aligned}
$$

Equalities in (3.2), (3.3), and (3.4) are attained if we take

$$
f(z)=\frac{z}{1 \pm a z+\frac{\alpha}{2} z^{2}} \in S(\alpha), \quad(0 \leq a \leq \sqrt{2 \alpha}) .
$$

Proof. In view of (1.5), we have

$$
z\left(\frac{z}{f(z)}\right)^{\prime \prime} \prec \alpha z
$$

Applying the lemma to (3.6), we find that

$$
\left(\frac{z}{f(z)}\right)^{\prime}+a_{2} \prec \alpha z .
$$

By using a result of Hallenbeck and Ruscheweyh [1, Thm. 1], (3.7) gives

$$
\frac{1}{z} \int_{0}^{z}\left[\left(\frac{t}{f(t)}\right)^{\prime}+a_{2}\right] d t \prec \frac{\alpha}{2} z
$$

i.e.,

$$
\frac{z}{f(z)}=1-a_{2} z+\frac{\alpha}{2} z w(z)
$$

where $w(z)$ is analytic in $E$ and $|w(z)| \leq|z|(z \in E)$ by Schwarz lemma.

Now, from (3.9), we can easily derive the inequalities (3.2), (3.3), and (3.4).

THEOREM 3. Let $f(z) \in S(\alpha)$ and have the form

$$
f(z)=z+a_{3} z^{3}+a_{4} z^{4}+\cdots .
$$

(a) If $2 / \sqrt{5} \leq \alpha \leq 2$, then $f(z)$ is star-like in $|z|<\sqrt{2 / \alpha} \cdot 1 / \sqrt[4]{5}$;

(b) If $\sqrt{3}-1 \leq \alpha \leq 2$, then $\operatorname{Re} f^{\prime}(z)>0$ for $|z|<\sqrt{(\sqrt{3}-1) / \alpha}$.

Proof. If we put

$$
p(z)=\frac{z^{2} f^{\prime}(z)}{f^{2}(z)}=1+p_{2} z^{2}+\cdots,
$$


then, by (1.5), we have

$$
z p^{\prime}(z)=-z^{2}\left(\frac{z}{f(z)}\right)^{\prime \prime} \prec \alpha z,
$$

and it follows, from the lemma, that

$$
p(z) \prec 1+\alpha z,
$$

which implies that

$$
\left|\frac{z^{2} f^{\prime}(z)}{f^{2}(z)}-1\right| \leq \alpha|z|^{2}, \quad(z \in E) .
$$

(a) Let $2 / \sqrt{5} \leq \alpha \leq 2$ and

$$
|z|<r_{1}=\sqrt{\frac{2}{\alpha}} \cdot \frac{1}{\sqrt[4]{5}} .
$$

Then, by (3.14), we have

$$
\left|\arg \frac{z^{2} f^{\prime}(z)}{f^{2}(z)}\right|<\arcsin \frac{2}{\sqrt{5}} .
$$

Also, from (3.2) in Theorem 2 with $a_{2}=0$, we obtain

$$
\left|\frac{z}{f(z)}-1\right|<\frac{\alpha}{2} r_{1}^{2}
$$

and so

$$
\left|\arg \frac{z}{f(z)}\right|<\arcsin \frac{1}{\sqrt{5}} .
$$

Therefore, it follows, from (3.16) and (3.18), that

$$
\left|\arg \frac{z f^{\prime}(z)}{f(z)}\right| \leq\left|\arg \frac{z^{2} f^{\prime}(z)}{f^{2}(z)}\right|+\left|\arg \frac{z}{f(z)}\right|<\arcsin \frac{2}{\sqrt{5}}+\arcsin \frac{1}{\sqrt{5}}=\frac{\pi}{2}
$$

for $|z|<r_{1}$. This proves that $f(z)$ is star-like in $|z|<r_{1}$.

(b) Let $\sqrt{3}-1 \leq \alpha \leq 2$ and

$$
|z|<r_{2}=\sqrt{\frac{\sqrt{3}-1}{\alpha}}
$$

Then we have

$$
\begin{aligned}
\left|\arg f^{\prime}(z)\right| & \leq\left|\arg \frac{z^{2} f^{\prime}(z)}{f^{2}(z)}\right|+2\left|\arg \frac{z}{f(z)}\right|<\arcsin \left(\alpha r_{2}^{2}\right)+2 \arcsin \left(\frac{\alpha}{2} r_{2}^{2}\right) \\
& =\arcsin (\sqrt{3}-1)+2 \arcsin \left(\frac{\sqrt{3}-1}{2}\right)=\frac{\pi}{2} .
\end{aligned}
$$

Thus, $\operatorname{Re} f^{\prime}(z)>0$ for $|z|<r_{2}$.

COROLlary 3. Let $f(z) \in S(\alpha)$ and have the form (3.10)

(a) if $0<\alpha \leq 2 / \sqrt{5}$, then $f(z)$ is star-like in $E$;

(b) if $0<\alpha \leq \sqrt{3}-1$, then $\operatorname{Re} f^{\prime}(z)>0$ for $z \in E$. 


\section{REFERENCES}

[1] D. J. Hallenbeck and S. Ruscheweyh, Subordination by convex functions, Proc. Amer. Math. Soc. 52 (1975), 191-195. MR 51 10603. Zbl 311.30010.

[2] M. Nunokawa, M. Obradovic, and S. Owa, One criterion for univalency, Proc. Amer. Math. Soc. 106 (1989), no. 4, 1035-1037. MR 91h:30020. Zbl 672.30022.

[3] M. Obradovic, N. N. Pascu, and I. Radomir, A class of univalent functions, Math. Japon. 44 (1996), no. 3, 565-568. MR 97i:30016. Zbl 868.30013.

[4] S. Ozaki and M. Nunokawa, The Schwarzian derivative and univalent functions, Proc. Amer. Math. Soc. 33 (1972), 392-394. MR 45 8821. Zbl 233.30011.

[5] T. J. Suffridge, Some remarks on convex maps of the unit disk, Duke Math. J. 37 (1970), 775-777. MR 42\#4722. Zbl 206.36202.

YANG: Department of Mathematics, Suzhou University, Suzhou 215006, ChinA

LiU: WATER CONSERVANCY COLLEge, YANGZHOU UNIVERSITY, YANGZHOU 225009, CHINA 


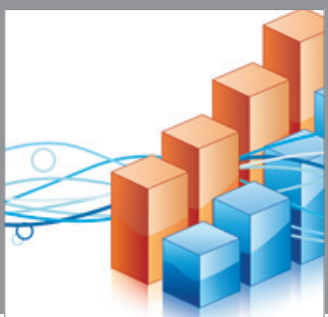

Advances in

Operations Research

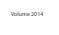

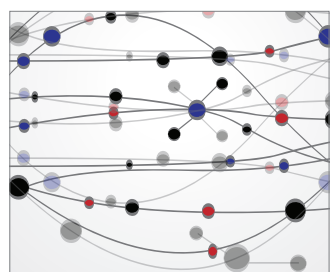

\section{The Scientific} World Journal
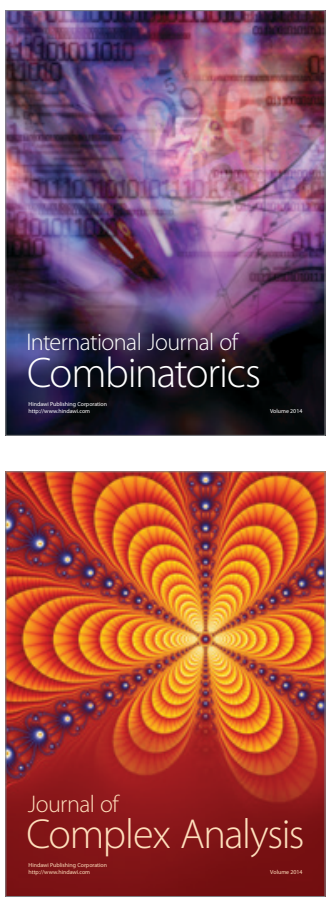

International Journal of

Mathematics and

Mathematical

Sciences
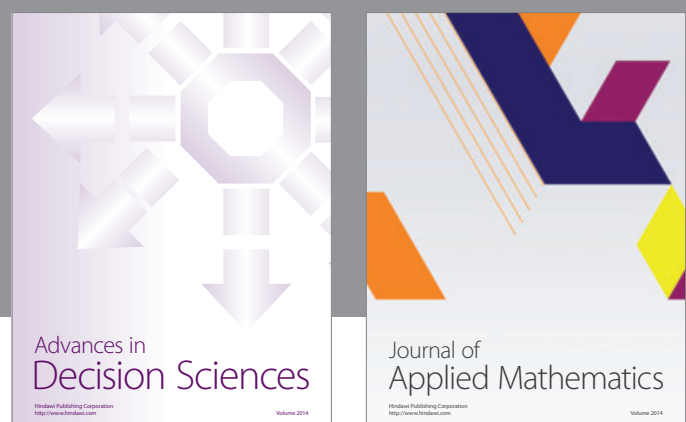

Journal of

Applied Mathematics
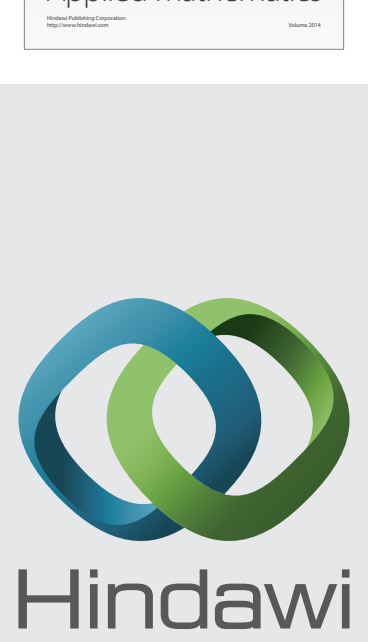

Submit your manuscripts at http://www.hindawi.com
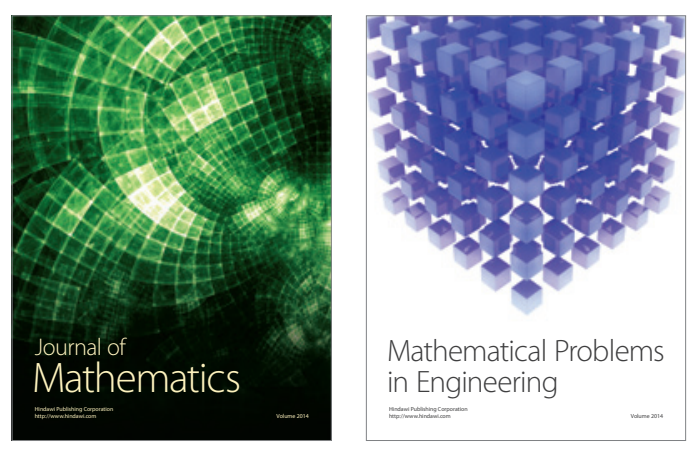

Mathematical Problems in Engineering
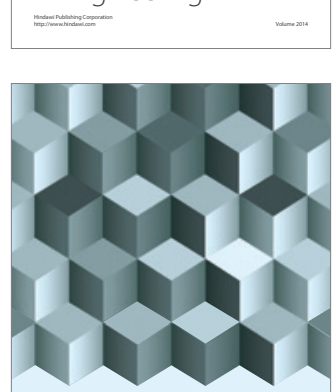

Journal of

Function Spaces
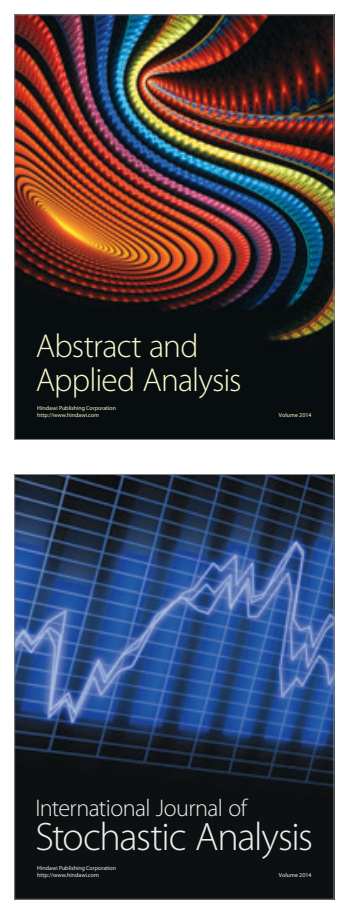

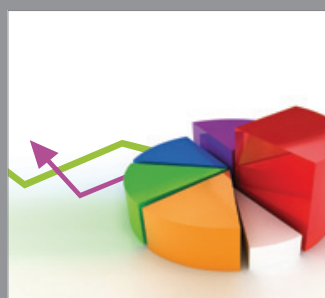

ournal of

Probability and Statistics

Promensencen
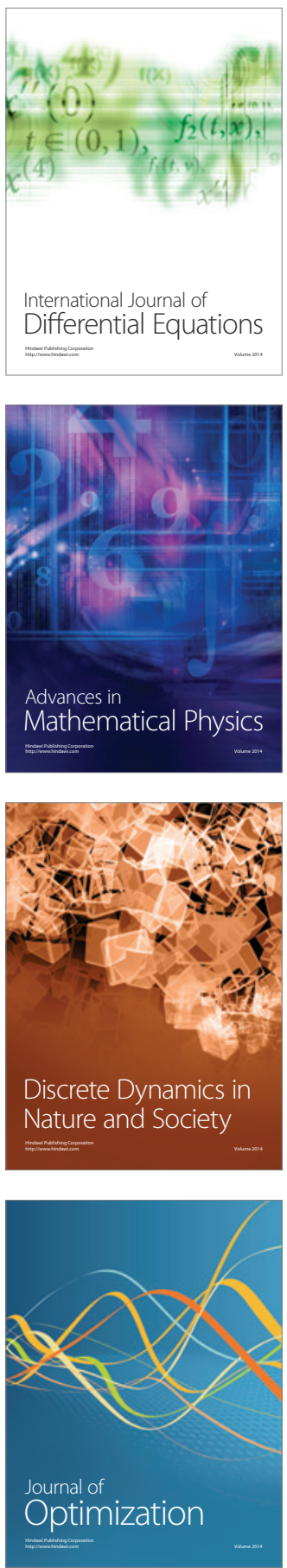